\title{
A retrospective analysis of adverse drug reactions reported at a tertiary care hospital in South India
}

\author{
Hemavathy G., Jeyalalitha Rathinam*, Preethi A., Divakar R.
}

Department of Pharmacology, Govt. Stanley Medical College, Chennai, Tamil Nadu, India

Received: 22 May 2018

Accepted: 29 May 2018

*Correspondence to:

Dr. Jeyalalitha Rathinam, Email: jeya0909@gmail.com

Copyright: (C) the author(s), publisher and licensee Medip Academy. This is an openaccess article distributed under the terms of the Creative Commons Attribution NonCommercial License, which permits unrestricted noncommercial use, distribution, and reproduction in any medium, provided the original work is properly cited.

\begin{abstract}
Background: Adverse drug reactions (ADRs) have a major impact on public health. Pharmacovigilance has become an integral part of pharmacotherapy. This study has been undertaken to retrospectively analyze the various adverse drug reactions and to promote the reporting of ADRs among the healthcare providers. Methods: A retrospective analysis of the reported ADRs over a period of 3 years at a tertiary care hospital, in Chennai was done. Data related to the number of adverse drug reactions, the demographic particulars, details on the drugs administered, type of ADRs, serious events and prevention strategies undertaken was analyzed. ADRs were assessed for their causality, severity, and preventability as per the standard criteria.

Results: A total of 128 suspected ADRs were found to be reported over a period of 3 years. $81.25 \%$ ADRs were found to be of mild severity using the Hartwigs scale of assessment, $71.09 \%$ were classified as possible using the Naranjo's causality assessment, the outcome of $63.28 \%$ were found to be recovering from the ADR and $41.40 \%$ were under the probably preventable category. The most common ADRs were the skin reactions. The antimicrobial agents were found to have caused the highest number $(58.59 \%)$ of ADRs followed by NSAIDs $(14.84 \%)$ and the antihypertensive drugs $(14.06 \%)$.

Conclusions: The antimicrobial agents were associated with ADRs in majority of the patients. The commonly reported ADR s were the skin reactions.
\end{abstract}

Keywords: Adverse Drug Reactions, Antimicrobial agents, Causality, Preventability, Pharmacovigilance, Severity, Skin reactions

\section{INTRODUCTION}

The advent of vast majority of the drugs in the recent years, have proven to be beneficial in a variety of much difficult to treat disorders. But at the same time there is always a lurking danger of serious adverse drug reactions associated with most of the drugs which are not evident during the initial stages of drug development. In addition to the inherent mechanisms, inappropriate use of drugs is also the major cause of adverse drug reactions (ADRs). The WHO defines an adverse drug reaction as "a response to a drug which is noxious and unintended and which occurs at doses normally used in man for prophylaxis, diagnosis, or therapy of disease or for the modification of physiologic function."1 ADRs are a major cause of morbidity and mortality, and leading cause of hospital admission. ${ }^{2}$ ADRs are the 4th leading cause of death ahead of pulmonary disease, diabetes, AIDS, pneumonia, accidents, and automobile deaths. ${ }^{3}$ Serious ADRs account for $6.7 \%$ of all hospital admissions and occur in $10-20 \%$ of hospitalized patients. $^{4,5}$ A study in south India has shown that admissions due to ADRs accounted for $0.7 \%$ of total admissions and deaths due to ADRs accounted for $1.8 \%$ of total ADRs. ${ }^{6}$ Studies have also revealed that ADRs are leading to hospitalization and constitute a significant economic burden on patients in India. ${ }^{7}$ ADRs have a major impact on public health and have become a global problem 
of major concern. None of the prescribed medications are completely safe and the majority of ADRs are preventable. In view of that, pharmacovigilance has become an integral part of pharmacotherapy. The ultimate aim of pharmacovigilance is to improve health care and safety in relation to the use of medicines. Pharmacovigilance is a pharmacological science related to the detection, assessment, understanding and prevention of adverse effects, particularly long-term and short-term adverse effects of medicines (WHO-Essential Medicines and Health Products, 2002). Adverse drug reactions are highly variable and therefore, robust pharmacovigilance monitoring is needed in the population of different race and ethnicity. ${ }^{8}$ Even though the pharmacovigilance programme was launched as early as 2004 , the essential population of prescribing physicians and other health care personnel are yet to be fully involved in the programme. This study has been undertaken to retrospectively analyze the various ADRs reported at a tertiary care hospital with an aim to collect data on different types of ADRs, the major class of suspect drugs involved in ADRs, to analyze and evaluate patterns of ADRs and to assess the reporting trends among the healthcare providers.

\section{METHODS}

A retrospective analysis of the ADRs reported over a period of 3 years at a tertiary care hospital, in Chennai was done. The trial protocol was submitted to the institutional ethics committee and the study was initiated on approval from the institutional ethics board. All the ADRs that were reported from the inpatient and outpatient departments were included for assessment. Data related to the ADRs were collected from the filled in ADR reporting forms and the case records. The following data with regard to total number of ADRs, the various demographic particulars of the patients including age, sex, clinical diagnosis, the treatment given, the suspect drug administered, details of route of administration of the drug, dosing frequency, history of previous drug allergy to the same drug or any other drug or other allergies, family history, the ADR reported, the details of the type of ADR, any serious events, time of occurrence of the adverse effect, time period of report of the effect and the treatment measures along with further prevention strategies undertaken was analysed. The details on co administration of other drugs and drug interactions if available was also assessed along with history of comorbid conditions. The severity of the
ADR was assessed using the Hartwigs criterion and the causality assessment was done using the Naranjos probability scale of assessment. The outcome of the ADR was recorded as not recovered, recovered, recovering, and unknown. The occurrence of ADRs related to specific drug group was analysed and the preventability assessment was done using the modified Schumock and Thornton scale which classifies the ADRs into definitely preventable, probably preventable and not preventable.

\section{RESULTS}

Descriptive statistics was used for data analysis. The data obtained was analysed using percentage calculations. A total of 128 ADRs were found to be reported over a period of 3 years from the data that was collected. The data was analysed and it was found that $19.53 \%$ of the patients belonged to the paediatric age group. (The highest frequency of occurrence $(20.31 \%)$ was found to occur in the age group of $31-40$ years followed by $19.53 \%$ in the age group of $19-30$ years, and $18.75 \%$ in the age group of 51-60 years. The male patients were found to be more affected $(23.94 \%)$ in the age group of 51-60 years. $6 \%$ of the patients were found to have developed ADRs over the age of 60 years (Table 1$)$.

Table 1: Age and gender frequency.

\begin{tabular}{|llll|}
\hline $\begin{array}{l}\text { Age } \\
\text { group }\end{array}$ & Frequency*(\%) & $\mathbf{F} * *(\%)$ & $\mathbf{M} * * *(\%)$ \\
\hline $1-10$ & $15(11.71)$ & $7(12.28)$ & $8(11.26)$ \\
\hline $11-18$ & $10(7.81)$ & $7(12.28)$ & $3(4.22)$ \\
\hline $19-30$ & $25(19.53)$ & $10(17.54)$ & $15(21.12)$ \\
\hline $31-40$ & $26(20.31)$ & $14(24.56)$ & $12(16.90)$ \\
\hline $41-50$ & $22(17.18)$ & $8(14.03)$ & $14(19.71)$ \\
\hline $51-60$ & $24(18.75)$ & $7(12.28)$ & $17(23.94)$ \\
\hline$>60$ & $6(4.68)$ & $4(7.01)$ & $2(2.81)$ \\
\hline
\end{tabular}

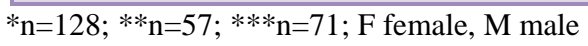

Table 2: Hartwigs severity scale.

\begin{tabular}{|lll|}
\hline Severity & Frequency & Percentage (\%) \\
\hline Mild & 104 & 81.25 \\
\hline Moderate & 18 & 14.06 \\
\hline Severe & 6 & 4.68 \\
$\mathrm{n}=128$ & & \\
\hline
\end{tabular}

Table 3: Severity based on organ system affected.

\begin{tabular}{|lllllllll|} 
Severity & $\begin{array}{l}\text { CNS } \\
\mathbf{n = 5}\end{array}$ & $\begin{array}{l}\text { CVS } \\
\mathbf{n = 1 8}\end{array}$ & $\begin{array}{l}\text { DERM } \\
\mathbf{n = 7 4}\end{array}$ & $\begin{array}{l}\text { GIT } \\
\mathbf{n = 4}\end{array}$ & $\begin{array}{l}\text { Hepatic } \\
\mathbf{n = 3}\end{array}$ & $\begin{array}{l}\text { Immune } \\
\text { sys*; } \mathbf{n = 1 9}\end{array}$ & $\begin{array}{l}\text { RS } \\
\mathbf{n = 2}\end{array}$ & $\begin{array}{l}\text { Others } \\
\mathbf{n = 3}\end{array}$ \\
\hline Mild & 4 & 16 & 62 & 1 & 3 & 14 & 2 & 2 \\
\hline Moderate & 1 & 2 & 8 & 3 & 0 & 3 & 0 & 1 \\
\hline Severe & 0 & 0 & 4 & 0 & 0 & 2 & 0 & 0 \\
\hline$\%$ & 3.90 & 14.06 & 57.81 & 3.12 & 2.34 & 14.84 & 1.56 & 2.34 \\
\hline
\end{tabular}

Total $n=128$; mild $n=104$; moderate $n=18$; severe $n=6$; Immune sys Immune system 
The adverse drug reactions were classified as mild, moderate and severe using the ADR Hartwigs severity assessment scale. (Modified Hartwig and Siegel) (Table 2).

It was found that $81.25 \%$ of the ADRs reported were of mild nature, $14.06 \%$ was of moderate nature and $4.68 \%$ were severe reactions. The severity was scored according to the organ system affected (Table 3 ).

Table 4: Naranjo's causality assessment.

\begin{tabular}{|ll|l|}
\hline Causality & Frequency $\mathbf{n = 1 2 8}$ & Percentage $(\boldsymbol{\%})$ \\
\hline Definite & 1 & 0.78 \\
\hline Probable & 36 & 28.12 \\
\hline Possible & 91 & 71.09 \\
\hline Doubtful & 0 & 0 \\
\hline
\end{tabular}

It was found that the highest frequency of $57.81 \%$ was found to be associated with skin, followed by the immune system (14.84\%) and the cardiovascular system (14.06\%). The least number of reactions were found to occur in association with the respiratory system (1.56\%). Causality assessments was done using the Naranjo's causality assessment scale (Table 4).

The highest scoring was found to be of possible nature $(71.09 \%$ ) while $0.78 \%$ of the reactions were found to be of definite likelihood and $28.12 \%$ were found to be of probable scoring. The outcome of various ADRs as available from the data were recorded as non recovered, recovering, recovered and unknown (Table 5).

\section{Table 5: Outcome assessment.}

\begin{tabular}{|lll|}
\hline Outcome & Frequency $\mathbf{n = 1 2 8}$ & Percentage (\%) \\
\hline Not recovered & 8 & 6.25 \\
\hline Recovered & 25 & 19.53 \\
\hline Recovering & 81 & 63.28 \\
\hline Unknown & 14 & 10.93 \\
\hline
\end{tabular}

Table 6: Drugs associated with the ADRs.

\begin{tabular}{|c|c|c|}
\hline Drug classification & Frequency $(\%)$ & Drugs \\
\hline Anti hypertensive & $18(14.06)$ & Amlodipine, enalapril, nifedipine \\
\hline Antimicrobial & $75(58.59)$ & $\begin{array}{l}\text { Cefotaxime, ceftriaxone, cefixime, ciprofloxacin, ofloxacin, metronidazole, } \\
\text { cloxacillin, cotrimoxazole, azithromycin, erythromycin, ampicillin, } \\
\text { doxycycline, INH, rifampicin, dapsone, }\end{array}$ \\
\hline NSAIDS /others & $19(14.84)$ & Diclofenac, ibuprofen, aceclofenac, paracetamol, tramadol sulfasalazine, \\
\hline Antiepileptic & $9(7.03)$ & Carbamazepine, phenytoin, levatiracetam, \\
\hline Antifibrinolytic & $3(2.34)$ & Streptokinase \\
\hline Antipsychotics & $1(0.78)$ & Risperidone \\
\hline Diuretics & $1(0.78)$ & Spironolactone \\
\hline $\mathrm{H} 2$ antihistaminic & $1(0.78)$ & Ranitidine \\
\hline Immunosuppressant & $1(0.78)$ & Azathioprine \\
\hline
\end{tabular}

$\mathrm{n}=128$; ADR s Adverse drug reactions; NSAIDs Non steroidal anti-inflammatory drugs

It was found that $6.25 \%$ were non recovered, $19.53 \%$ were reported to be recovered, $63.28 \%$ were recovering from the ADR and the details of $10.94 \%$ was unknown. The antimicrobial agents were found to have caused the highest number (58.59\%) of ADRs followed by NSAIDs (14.84\%) and the antihypertensive drugs (14.06\%) (Table 6).

Table 7: Preventability assessment.

\begin{tabular}{|lll|}
\hline ADR & $\begin{array}{l}\text { Frequency } \\
\mathbf{n = 1 2 8}\end{array}$ & $\begin{array}{l}\text { Percentage } \\
(\%)\end{array}$ \\
\hline Definitely preventable & 0 & 0 \\
\hline Probably preventable & 53 & 41.40 \\
\hline Not preventable & 75 & 58.59 \\
\hline
\end{tabular}

The most common ADR associated with the use of antimicrobial agents was skin reactions. The Schumock and Thornton scale was used for preventability assessment which classifies the ADRs into definitely preventable, probably preventable and not preventable (Table 7).

\section{DISCUSSION}

This study was conducted to analyse and to clinically evaluate the pattern of various adverse drug reactions recorded over a period of 3 years in a tertiary care setup, and to promote the reporting of ADRs along with an awareness about the ADR reporting among the healthcare providers. The data obtained was analyzed with reference to the various demographic details, severity of the adverse drug reactions and its relation to various organ systems involved, causality assessment using the Naranjo scale, assessment of the outcome of the various adverse drug reactions, preventability assessment of various ADRs and the common group of drugs involved in the ADRs. There 
was an increase in the number of cases reported during third year of study period in comparison to the first two years of study period. It was found that $19.53 \%$ of the patients belonged to the paediatric age group. The highest frequency of $20.31 \%$ was found to occur in the age group of $31-40$ years followed by $19.53 \%$ in the age group of 19 30 years, $18.75 \%$ in the age group of 51-60 years. It has been reported from studies that the incidence of ADR is much more in geriatric, pediatric and female patients. ${ }^{9}$ In the present study the male patients were found to be more affected $(23.94 \%)$ in the age group of 51-60 years, followed by male patients $(21.12 \%)$ in the age group of 19 30 years among the adult population while there was a female preponderance among the paediatric age group. $6 \%$ of the patients were found to have developed ADRs over the age of 60 years. Elderly and hospitalized patients have been reported to be more susceptible to ADRs than the adult population $(16.6 \%$ vs. $4.1 \%) .{ }^{10}$ The adverse drug reactions were classified as mild, moderate and severe using the ADR severity assessment scale of Hartwigs. ${ }^{11}$ It was found that $81.25 \%$ of the ADRs reported were of mild nature, $14.06 \%$ were moderate and $4.68 \%$ were severe reactions. The severity was scored according to the organ system affected. It was found that the highest frequency of $57.81 \%$ was associated with dermatology, followed by the Immune system $(14.84 \%)$ and the cardiovascular system $(14.06 \%)$. The least number of reactions were found to occur in association with the respiratory system (1.56\%). It has been reported that the skin reactions are the most common ADRs associated with drug use from several studies. $^{12}$

Causality assessments was done using the Naranjo's causality assessment scale which classifies drug reactions into definite, probable, possible and doubtful ADR. The Naranjo Algorithm is a questionnaire designed by Naranjo et al for determining the likelihood of whether an ADR is actually due to the drug rather than the result of other factors. It is also called the Naranjo Scale or Naranjo Score. ${ }^{13}$ The highest scoring was found to be of possible nature $(71.09 \%)$, while $0.78 \%$ of the reactions were found to be of definite likelihood and $28.12 \%$ were found to be of probable scoring. The Naranjo system is a commonly used tool of scoring but difficulties in answering some of the questions in the tool may artificially lower the causality score, thus reducing its sensitivity. ${ }^{14}$ The outcome of various ADRs as available from the data were recorded as non recovered, recovering, recovered and unknown. It was found that $6.25 \%$ were non recovered, $19.53 \%$ were reported to be recovered, $63.28 \%$ were recovering from the ADR and the details of $10.93 \%$ was unknown. This was a retrospective study and the details on the ultimate outcome of the reactions was not obtainable. The various drug classes that were found to be associated with the ADRs are the antimicrobial agents, nonsteroidal anti-inflammatory drugs, antiepileptics, antihypertensives, antifibrinolytics, $\mathrm{H}_{2}$ blockers, antipsychotics, immunosuppressants and diuretics. The antimicrobial agents were found to have caused the highest number $(58.59 \%)$ of ADRs followed by NSAIDs (14.84\%) and the antihypertensive drugs
$(14.06 \%)$. Several studies have pointed that antibiotics were the most accounted drug class in ADR occurrence. ${ }^{15,16}$

The most common ADRs associated with the use of antimicrobial agents were the skin reactions. Several studies have already pointed out that skin reaction is the commonly occurring adverse drug reactions. ${ }^{17}$ The skin reactions were characterised by rashes, erythema, urticaria and pruritus. FDE were reported in 5 patients out of which two were due to diclofenac and one each caused by ciprofloxacin, erythromycin and cefixime. Two were bullous FDE probably due to diclofenac. There was a female preponderance with the skin reactions as reported in several studies. Females are more susceptible to gastrointestinal and cutaneous allergic adverse drug reactions. ${ }^{18}$ The other ADRs that were reported were nausea, vomiting, diarrhoea, abdominal pain, giddiness, fever, chills and rigor, cracked lips, purulent discharge, dizziness and one report of anaphylaxis. The antiepileptic drug carbamazepine was associated with skin reactions and urticaria. Phenytoin was associated with skin rashes, urticaria and one reaction of toxic epidermo necrolysis [TEN] and steven johnsons syndrome. TEN was found to occur in a paediatric, male patient treated for epilepsy. The patient with steven Johnsons syndrome was a 23 year old female patient treated for epilepsy. SJS is reported to be common at extremes of ages. ${ }^{19}$ Pharmacogenomic markers have been identified for a growing number of drugs for serious ADRs, and implementation of pharmacogenomic testing has been advanced as a means to prevent the occurrence of some of these ADRs. ${ }^{20}$

Levetiracetam was associated with skin rashes. The antihypertensive drug enalapril was associated with cough and chest discomfort, while amlodipine and nifedipine was associated with pedal oedema. Streptokinase was found to be associated with skin reactions, NSAIDS and other analgesics were associated with skin rashes, vomiting abdominal pain, gastritis, black stools and bullous FDE. The antifungal drug fluconazole was associated with skin reactions, the antipsychotic drug risperidone was associated with loss of libido, spironolactone was found to cause gynecomastia in one patient, ranitidine was associated with urticaria, azathioprine was associated with chest discomfort, INH was associated with peripheral neuritis. The Schumock and Thornton scale was used for preventability assessment which classifies the ADRs into definitely preventable, probably preventable and not preventable. On evaluation of the chances of preventability of ADRs, it was found that $41.40 \%$ were probably preventable ADR s while $58.59 \%$ were not preventable ADRs. A coordinated system of identifying the ADRs early in the course of treatment and an update on the preventable ADRs mandates an active participation of the entire health care system. Spontaneous reporting of ADRs and adverse events is an important tool for gathering the safety information for early detection. ${ }^{21}$ Limitation of the study is that it has been done as a retrospective study. The follow up on actual outcome was not possible. Complete 
details on the suspect drug and the other co administered drugs, was not available. Details on storage, prescribing, dispensing, administration and monitoring can be better inferred from a prospective study.

\section{CONCLUSION}

A total of 128 suspected ADRs were found to be reported over a period of 3 years. $81.25 \%$ ADRs were of mild severity, $71.09 \%$ were classified as possible natured using Naranjo's causality, the outcome of $63.28 \%$ were found to be recovering from the ADR and $41.40 \%$ were under probably preventable category. The most common ADRs were the skin reactions. The antimicrobial agents were found to have caused the highest number $(58.59 \%)$ of ADRs followed by NSAIDs (14.84\%) and the antihypertensive drugs (14.06\%). More sensitization programs involving prescribing physicians and a coordinated functioning of prescribing physicians and the pharmacovigilance personnel's can improve the trend of reporting ADRs.

\section{ACKNOWLEDGEMENTS}

The authors would like to thank the staff, Stanley medical college, who helped with the collection of data on ADR. We render our sincere thanks to the NPVPI center for the motivational guidance offered. Also, author would like to thank to the library staff and facility of Stanley Medical College.

\section{Funding: No funding sources}

Conflict of interest: None declared

Ethical approval: The study was approved by the Institutional Ethics Committee

\section{REFERENCES}

1. World Health Organization. Safety of Medicines-A Guide to Detecting and Reporting Adverse Drug Reactions-Why Health Professionals Need to Take Actions. Geneva: World Health Organization; 2002. Available at: http:// www. apps. who.int/ medicinedocs/ en/d/Jh2992e/6.html. Accessed on 2018 May 12

2. Sultana J, Cutroneo P, Trifirò G. Clinical and economic burden of adverse drug reactions. J Pharmacol Pharmacother. 2013;4:S73-7.

3. Preventable Adverse Drug Reactions: A Focus on Drug Interactions Available at: https://www.fda.gov/Drugs/DevelopmentApprovalPr ocess/DevelopmentResources/DrugInteractionsLabeli ng/ucm110632.htm . Accessed on 2018 May 11.

4. Shrivastava M, Uchit G, Chakravarti A, Joshi G, Mahatme M, Chaudhari H. Adverse drug reactions reported in Indira Gandhi Government Medical College and Hospital, Nagpur. J Assoc Physicians India. 2011;59:296-9.

5. Prajapati K, Desai M, Shah S, Panchal J, Kapadia J, Dikshit R. An analysis of serious adverse drug reactions at a tertiary care teaching hospital. Perspect Clin Res. 2016;7:181-6.

6. Ramesh M, Pandit J, Parthasarathi G. Adverse drug reactions in a south Indian hospital. Their severity and cost involved. Pharmacoepidemiol Drug Saf. 2003;12:687-92.

7. Khan FA, Nizamuddin S, Najmul H, Mishra H. A prospective study on prevalence of adverse drug reactions due to antibiotics usage in otolaryngology department of a tertiary care hospital in North India. Int J Basic Clin Pharmacol. 2013;2:548-53.

8. Lihite RJ, Lahkar M. An update on the Pharmacovigilance Programme of India. Front. Pharmacol. 2015;6:194.

9. Inocencia MM, Mercedes GL. A prospective study of adverse drug reactions in hospitalized children. $\mathrm{Br} \mathbf{J}$ Clin Pharmacol. 2009;47:681-8.

10. Beijer HJM, de Blaey CJ. Hospitalisations caused by adverse drug reactions: A meta-analysis of observational studies. Pharm World Sci. 2002;24:4654.

11. Hartwig SC, Siegel J, Schneider PJ. Preventability and severity assessment in reporting ADRs. American J of Hospital Pharm. 1992;49:2229-32.

12. Segal AR, Doherty KM, Leggott J, Zlotoff B. Cutaneous Reactions to Drugs in Children. Pediatrics. 2007;120(4):e1082-96.

13. Naranj OCA, Busto U, Sellars EM, Sandor P, Ruiz I, Roberts EA, et al. Method for Estimating the Probability of Adverse Drug Reactions. Clin Pharmacol Ther. 1981;30:239-45.

14. Gallagher RM, Kirkham JJ, Mason JR, Bird KA, Williamson PR, Nunn AJ, et al. Development and inter-rater reliability of the Liverpool adverse drug reaction causality assessment tool. PLoS One. 2011 Dec 14;6(12):e28096.

15. Shamna M, Dilip C, Ajmal M, Mohan PL, Shinu C, Jafer CP, et al. A prospective study on Adverse Drug Reactions of antibiotics in a tertiary care hospital. Saudi Pharma J. 2014 Sep 1;22(4):303-8.

16. Sre Akshaya S, Srihitha. An Epidemiological Study on Adverse Drug Reactions in Indian Population: MetaAnalysis. IJPCR. 2017;9(10):654-9.

17. Farshchian M, Ansar A, Zamanian A, RahmatpourRokni G, Kimyai-Asadi A, Farshchian M. Druginduced skin reactions: a 2-year study. Clin Cosmet Investig Dermatol. 2015;8:53-56.

18. Sharma VK, Sethuraman G, Kumar B. Cutaneous adverse drug reactions: clinical pattern and causative agents a 6-year series from Chandigarh, India. J Postgrad Med. 2001;47:95

19. Patel PP, Gandhi AM, Desai CK, Desai MK, Dikshit RK. An analysis of drug induced Stevens-Johnson syndrome. The Ind J of Me Rese. 2012;136(6):10513 .

20. Chan SL, Ang X, Sani LL, Ng HY, Winther MD, Liu $\mathrm{JJ}$, et al. Prevalence and characteristics of adverse drug reactions at admission to hospital: a prospective observational study. Bri J of Clin Pharmac. 2016 Dec $1 ; 82(6): 1636-46$. 
21. Suke SG, Kosta P, Negi H. Role of Pharmacovigilance in India: An overview. Online J Public Health Inform. 2015;7(2):e223.
Cite this article as: Hemavathy $\mathrm{G}$, Rathinam J, Preethi A, Divakar R. A retrospective analysis of adverse drug reactions reported at a tertiary care hospital in South India. Int J Basic Clin Pharmacol 2018;7:1257-62. 